\title{
Melatonin Relieves Busulfan-Induced Spermatogonial Stem Cell Apoptosis of Mouse Testis by Inhibiting Endoplasmic Reticulum Stress
}

\author{
Yanhua Cui ${ }^{\mathrm{a}}$ Lipeng Ren ${ }^{\mathrm{a}}$ Bo Lia Jia Fang ${ }^{\mathrm{a}}$ Yuanxin Zhai ${ }^{\mathrm{a}}$ Xin He $\mathrm{He}^{\mathrm{a}}$ Enqi Du \\ Yiliang Miao ${ }^{b}$ Jinlian Hua ${ }^{a}$ Sha Peng ${ }^{a}$ \\ ${ }^{a}$ College of Veterinary Medicine, Shaanxi Centre of Stem Cells Engineering \& Technology, Northwest \\ A\&F University, Yangling, Shaanxi, ${ }^{b}$ College of Animal Sciences \& Technology, College of Veterinary \\ Medicine, Huazhong Agricultural University, Wuhan, China
}

\section{Key Words}

Melatonin • Busulfan $\bullet$ Spermatogonial stem cells $•$ Apoptosis $•$ Endoplasmic reticulum stress

\begin{abstract}
Background/Aims: Busulfan is commonly used for cancer chemotherapy. Although it has the advantage of increasing the survival rate of patients, it can cause male infertility via damaging the testes and reducing sperm counts. Therefore, the underlying mechanism should be explored, and new agents should be developed to protect the male reproductive system from busulfan-induced damage. Endoplasmic reticulum stress (ERS) is considered a key contributor to numerous pathologies. Despite several studies linking ERS to toxicants, studies have yet to determine whether ERS is a contributing factor to busulfan-induced testicular damage. Melatonin is a well-known broad-spectrum antioxidant, anti-inflammatory and antitumour agent, but the effects of melatonin on busulfan-induced ERS in mouse testes damage are less documented. Methods: The effects of melatonin were measured by immunofluorescence staining, Western blot, qRT-PCR analysis and flow cytometry assay. The underlying mechanism was investigated by measuring ERS. Results: We found that ERS was strongly activated in mouse testes (in vivo) and the C18-4 cell line (in vitro) after busulfan administration. ERSrelated apoptosis proteins such as caspase-12, CHOP and caspase- 3 were activated, and the expression of apoptotic proteins such as P53 and PUMA were upregulated. Furthermore, we investigated whether melatonin reduced the extent of damage to mouse testes and improved the survival rates of busulfan-treated mice. When exploring the underlying mechanisms, we found melatonin could counteract ERS by decreasing the expression levels of the ERS markers GRP78, ATF6, pIRE1 and XBP1 in mouse testes and mouse SSCs (C18-4 cells). Moreover, it blocked the activation of ERS-related apoptosis proteins caspase-12, CHOP and caspase-3 and suppressed P53 and PUMA expression stimulated by busulfan both in vivo and in vitro. Conclusion: Our results demonstrate that ERS is an important mediator for busulfan-induced apoptosis. The attenuation of ERS by melatonin can prevent busulfan-treated SSCs apoptosis
\end{abstract}

College of Veterinary Medicine, Shaanxi Centre of Stem Cells Engineering \& Technology Northwest A\&F University, Yangling 712100, Shaanxi (China)

Tel. +862987080069, E-Mail pengshacxh@163.com; jinlianhua@nwsuaf.edu.cn 


\section{Cellular Physiology Cell Physiol Biochem 2017;44:2407-2421

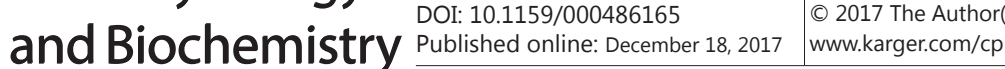

Cui et al.: Melatonin Relieves Busulfan-Induced Testis Damage

and protect busulfan-treated testes from damage. Thus, this study suggests that melatonin may alleviate the side effects of busulfan for male patients during clinical treatment.

\section{Introduction}

Advances in chemotherapy for cancer treatment in young patients have resulted in increased survival and cure rates [1]. However, fertility is often impaired by alkylating agents, such as busulfan, which is a commonly used chemotherapeutic drug [2-4]. Therefore, the quality of life and the preservation of fertility have emerged as significant issues [5]. New methods should be developed to prevent testicular damage induced by alkylating agents [6, 7].

The endoplasmic reticulum (ER) is an intracellular organelle that controls protein folding, intracellular calcium homeostasis, and lipid synthesis [8]. Environmental stresses and increased protein synthesis often lead to the accumulation of unfolded proteins in the ER, and this phenomenon is called ER stress (ERS). The ERS pathway consists of three different branches: activating transcription factor 6 (ATF6), inositol-requiring enzyme 1 (IRE1), and protein kinase RNA-like ER kinase (PERK) [9].

ERS performs a dualistic function. It can restore ER homeostasis, but if ERS persists chronically at high levels, cellular functions can be negatively affected [10]. Chronic ERS is considered a key contributor to numerous human diseases, such as diabetes and neurodegeneration $[11,12]$. Hence, targeting the components of ERS has been employed as a therapeutic strategy to control these ERS-associated pathologies $[13,14]$. The IRE1 signalling pathway protects against ERS and controls the development and survival of immune cells [15]. ATF6 activates the expression of a repertoire of antioxidant genes and serves an important role as a link between the ERS and oxidative stress gene programmes [16]. Tuberous sclerosis complex-1 ablation induces prominent endoplasmic ERS responses by activating the PERK signalling pathways [17]. Moreover, ERS can also be induced by alkylating agents in renal epithelial cells [18].

Melatonin is secreted by the pineal gland, which is regulated by dark-light and seasonal cycles in mammals [19]. It acts as an antioxidant by reducing oxidative stress and increasing the activity of antioxidant enzymes in the body [20]. Melatonin protects melanocytes from DNA damage and oxidative stress through activation of NRF2 and its target enzymes [21]. It is well reported that melatonin can ameliorate ischaemic brain injury, preserve the functional integrity of the blood-brain barrier, and induce neurogenesis and cell proliferation through a receptor-dependent mechanism [22].

Melatonin is also involved in ER homeostasis [23]. It enhances the expression of the ERS proteins ATF6 and CHOP, improves survival rates, and successfully attenuates liver injury [24]. Furthermore, melatonin treatment alleviates ERS during bleomycin-induced pulmonary fibrosis [25]. Melatonin affects the regulation of testicular development and male reproduction by stimulating the secretion of gonadotropins and testosterone [26]. It also prevents cisplatin-induced primordial follicle loss [27]. In addition, the research recently published by our group has reported that melatonin has beneficial effects on oxidative apoptosis of mouse SSCs induced by busulfan [28]. Therefore, we aim to assess whether ERS is involved in busulfan-induced SSC apoptosis and testicular damage. The present study will provide a theoretical basis for alleviating the side effects caused by busulfan in clinical cancer treatment.

In this study, the beneficial effects of melatonin on busulfan-induced testicular damage and mouse spermatogonial stem cell (SSC) apoptosis were demonstrated. Our results revealed that the presence of melatonin directly provided resistance to busulfan-induced apoptosis and correlated with ERS. In vitro and in vivo evidence demonstrated that the administration of melatonin could ameliorate testicular damage caused by busulfan. Therefore, melatonin might be useful as a potential drug to counteract the side effects of busulfan because of its advantages, including high efficiency, low toxicity and endogenous effects. 


\section{Cellular Physiology Cell Physiol Biochem 2017;44:2407-2421 \begin{tabular}{l|l|l}
\cline { 2 - 3 } DOI: 10.1159/000486165 & (c) 2017 The Author(s). Published by S. Karger AG, Basel
\end{tabular} Published onlıne: December 18, 2017 www.karger.com/cpb}

Cui et al.: Melatonin Relieves Busulfan-Induced Testis Damage

\section{Materials and Methods}

Animal experiments

Experiments were performed on healthy eight-week-old ICR male mice weighing between 25 and $30 \mathrm{~g}$. The mice were obtained from the animal centre of the Fourth Military Medical University and were housed in wire cages at $25^{\circ} \mathrm{C}$ in a $12 \mathrm{~h} / 12 \mathrm{~h}$ light/dark cycle at $70 \%$ humidity and fed ad libitum. The mice were maintained and the experiments were completed in accordance with the Guide for the Care and Use of Laboratory Animals at Northwest A\&F University.

In this experiment, busulfan and 4PBA were diluted in DMSO, and melatonin was dissolved in $1 \%$ ethanol (in normal saline). Eighty age-matched mice were randomly separated into four groups: the CON group received vehicle injection (DMSO), the BU group received a single busulfan treatment (30 mg/kg), the $\mathrm{BU}+\mathrm{MEL}$ group received melatonin $(10 \mathrm{mg} / \mathrm{kg} /$ day) after busulfan treatment for 4 weeks, and the BU+4PBA group received 4PBA (100 mg/kg/day) after busulfan treatment for 4 weeks.

\section{Cell experimental protocol}

C18-4 cells, which are type A spermatogonial stem cells, were cultured in Dulbecco's modified Eagle's medium/nutrient mixture F12 (DMEM/F12, Gibco, Grand Island, NY) supplemented with 10\% foetal bovine serum (FBS, Gibco), $2 \mathrm{mM}$ of L-glutamine (Invitrogen, Carlsbad, CA), and 100 unit/ml of penicillin and streptomycin (Invitrogen). The cells were subcultured every 3 days and maintained at $37^{\circ} \mathrm{C}$ in an incubator humidified with $5 \% \mathrm{CO}_{2}$. The cells were dissociated by treating with $0.25 \%$ trypsin-EDTA (Invitrogen) and reseeded into multi-well plates for subsequent analysis. The medium was changed every 2 d. In this procedure, busulfan was dissolved in DMSO to $10^{-4} \mu \mathrm{M}$. Melatonin was dissolved in $1 \%$ ethanol in physiological saline to $10^{-7}$ M. 4 PBA was dissolved in DMSO to $1 \mathrm{mM}$. Cells were cultivated with busulfan (BU), busulfan and melatonin (BU+MEL), or busulfan and 4PBA (BU+4PBA) for $24 \mathrm{~h}$ prior to the experiments.

\section{Histology analysis}

For histological analyses, testes were dissected from CON, BU, BU+MEL and BU+4PBA mice. After fixation in 4\% PFA solution, the samples were embedded in paraffin blocks. Sections were cut and then stained with haematoxylin and eosin (HE).

For sperm morphological analyses, cauda epididymal sperm from CON, BU, BU+MEL or BU+4PBA mice were spread onto slides with PBS and air-dried. Sperm smears were stained with Giemsa.

\section{Immunofluorescence staining}

Immunofluorescence staining was performed as described in our previous studies [29]. The details of the antibodies used are listed in Table 1.

\section{Western blot}

The testes were collected, and protein extracts were obtained after surgery. The proteins were quantified using a BCA protein assay kit (Beyotime, China). The proteins were separated through SDSPAGE and subsequently transferred to Immobilon NC membranes (Millipore, Boston, MA, USA). The membranes were blocked with $6 \%$ non-fat milk in TBST at room temperature, incubated with primary antibodies (the details are listed in Table 1) overnight at $4^{\circ} \mathrm{C}$ and washed thrice with TBST for $15 \mathrm{~min}$ each. The membranes were incubated at $37^{\circ} \mathrm{C}$ for 1 $\mathrm{h}$ with appropriate secondary antibodies, including goat anti-rabbit IgG-HRP (1:3000, Boster) and rabbit anti-mouse
Table 1. The primary antibody information

\begin{tabular}{lcccc}
\hline Antibody & Catalog No. & Corporate Brand & Dilution & Immusourcer \\
\hline PLZF & 12-9320-82 & eBioscience & $1: 200$ & Mouse IgG \\
VASA & ab13840 & Abcam & $1: 200$ & Rabbit IgG \\
ATF6 & D262665-0010 & Sangon Biotech & $1: 100$ & Rabbit IgG \\
XBP1 & E1916 & Santa cruz & $1: 100$ & Rabbit IgG \\
pIRE1 & bs-4308R & Biosynthesis Biotechnology & $1: 200$ & Rabbit IgG \\
CHOP & bs-20669R & Biosynthesis Biotechnology & $1: 200$ & Rabbit IgG \\
PUMA & BA1802 & Boster biological technology & $1: 200$ & Rabbit IgG \\
P53 & bs-0033R & Biosynthesis Biotechnology & $1: 200$ & Rabbit IgG \\
Caspase3 & bs-0081R & Biosynthesis Biotechnology & $1: 200$ & Rabbit IgG \\
Caspase12 & bs-1105R & Biosynthesis Biotechnology & $1: 200$ & Rabbit IgG \\
MT1 & bs-0027R & Biosynthesis Biotechnology & $1: 500$ & Rabbit IgG \\
MT2 & bs-0963R & Biosynthesis Biotechnology & $1: 500$ & Rabbit IgG \\
GRP78 & BA4293 & Boster biological technology & $1: 500$ & Rabbit IgG \\
Gapdh & KM9002T & Monoclonal & $1: 1000$ & Rabbit IgG \\
\hline
\end{tabular}




\section{Cellular Physiology \\ Cell Physiol Biochem 2017;44:2407-2421 and Biochemistry

IgG-HRP (1:2000, Boster) and then washed with TBST thrice for 15 min each time. Protein bands were detected using a Bio-Rad imaging system (BioRad, Hercules, CA, USA) and quantified using Quantity One (West Berkeley, CA, USA).

\section{qRT-PCR analysis}

Total RNA was extracted from testes using the Trizol reagent (Qiagen, Beijing, China) according to the manufacturer's instructions. Total RNA was reverse transcribed into cDNA using a Reverse Transcriptase Reagent kit (Thermo Scientific, Waltham, MA USA) according to the manufacturer's instructions. qRT-PCR analysis was conducted in triplicate on a CFX96 Real-time PCR system (Bio-Rad Ltd, Berkeley, CA, USA) according to the directions of the BioEasy SYBRGreen I RT-qPCR kit (Bioer Co. Ltd., Hangzhou, China). The qRT-PCR was performed as described previously [28]. Gapdh expression was used as the house-keeping control. The comparative CT method was used to measure the relative gene expression. The primers are listed in Table 2.

\section{Flow cytometry assay}

Cell cycle distribution was assessed by propidium iodide (PI) staining. Adherent cells were dissociated with $0.25 \%$ trypsinization. The samples were washed with PBS, stained with $50 \mu \mathrm{g} / \mathrm{ml}$ of PI and $50 \mu \mathrm{g} / \mathrm{ml}$ of RNase $\mathrm{A}$ at $37^{\circ} \mathrm{C}$ for $20 \mathrm{~min}$ and analysed through flow cytometry (Altra; Beckman Co.).

Cell apoptosis was evaluated through annexin V-FITC and PI staining. The cells for the apoptosis test were resuspended gently in $500 \mu \mathrm{l}$ of PBS. Then, $5 \mu \mathrm{l}$ of annexin V-FITC and $5 \mu \mathrm{l}$ of PI were added to the medium and mixed gently. The cells were incubated at room temperature for $10 \mathrm{~min}$ in the dark and subjected to FACS analysis.

The intracellular $\mathrm{Ca}^{2+}$ level was measured by using the Fluo-3 AM (Beyotime, China). Cells $\left(5 \times 10^{5}\right)$ were pretreated with BU, BU and MEL or 4PBA for $24 \mathrm{~h}$, loaded with Fluo-3 AM for $1 \mathrm{~h}$ and then subjected to flow cytometric analysis.

\section{Data analysis}

Statistical analyses were performed using one-way ANOVA with the Newman-Keuls multiple range test. Student's $t$ test was performed when only two pairs of data were compared. Data were represented as the mean $\pm \mathrm{SD}$, and statistical significance was expressed as follows: ${ }^{*} \mathrm{P}<0.05$, ${ }^{* *} \mathrm{P}<0.01$, and ${ }^{* * *} \mathrm{P}<0.001$. All data are representative of at least three different experiments and were analysed with GraphPad Prism (La Jolla, CA, USA).

\section{Results}

Melatonin alleviated busulfan-induced testicular damage in mice

To examine whether melatonin treatment influences the regeneration of spermatogenesis in the male mouse genital tract impaired by busulfan, we histopathologically analysed the testes and epididymis of different treatment groups. The results showed that the testicular mass of the busulfan-treated mice was reduced compared to control testes (48 $\pm 13 \%$ versus control group, $\mathrm{P}<0.05$, Fig. 1A). 4PBA works as a chemical chaperone by inhibiting ERS [30]. To determine whether the protective mechanism of melatonin is through suppression of ERS, we introduced 4PBA and found that the testicular weight was significantly increased in the melatonin and 4PBA treatment groups compared to busulfan-treated testes $(62 \pm 15 \%$ and $68 \pm 22 \%$ versus the busulfan-treated group, respectively, $\mathrm{P}<0.05$, Fig. 1B). Approximately 


\section{Cellular Physiology Cell Physiol Biochem 2017;44:2407-2421 \begin{tabular}{ll|l} 
DOI: 10.1159/000486165 & $\begin{array}{l}\text { ( 2) } 2017 \text { The Author(s). Published by S. Karger AG, Basel } \\
\text { www.karger.com/cpb }\end{array}$
\end{tabular} \\ Cui et al.: Melatonin Relieves Busulfan-Induced Testis Damage}

$50 \%$ of the mice died roughly 30 days after they were treated with busulfan, but the death rate was only $17 \%$ and $22 \%$ in the melatonin- and 4PBA-treated mice, respectively (Fig. 1C).

No histopathological abnormalities were observed in the control testes, and almost all seminiferous tubules were undergoing complete spermatogenesis. The busulfantreated testes consisted of thin seminiferous epithelia, large lumens, and testicular vein congestion. Most seminiferous tubules were devoid of germ cells, and numerous degenerating germ cells could be observed in the seminiferous tubules of the busulfan-treated testes. Melatonin significantly enhanced the spermatogenic recovery after busulfan treatment was administered (Fig. 1D). The proportion of tubules with spermatogenesis was declined in the busulfan treatment group compared to control testes $(\mathrm{P}<0.05)$. However, the percentage of seminiferous tubule with spermatogenesis in testes of the melatonin- and 4PBA-treated group were increased than that of the busulfan-treated group ( $48 \pm 28 \%$ and $57 \pm 7 \%$ versus busulfan-treated group, respectively, $\mathrm{P}<0.05$, Fig. $1 \mathrm{E}$ ). The quantitative data indicated that a significant number of germ cells lost in busulfan treatment group. Moreover, the total number of spermatogonial cells was drastically reduced in the busulfan treatment group compared to control group $(74 \pm 21 \%, P<0.05$, Fig. $1 F)$. Exposure of busulfan decreased the number of normal sperm per epididymis compared to control mice $(73 \pm 13 \%, \mathrm{P}<0.05)$. The count of normal sperm was increased 2.2 and 2.4 -fold in the melatonin- and 4PBA-rescued groups relative to the busulfan-treated group $(\mathrm{P}<0.05$, Figs. 1G-H). These results suggest that melatonin significantly prevented busulfan-induced testicular damage and spermatogonium loss.

\section{Melatonin inhibited the expression of ERS-related genes in testes}

To analyse the protective mechanism of melatonin for the testes against toxicity caused by busulfan, we used 4PBA and investigated the protein expression of the ERS indicators ATF6 and PERK in the testes. Consistent with histopathological findings, our results demonstrated that the intensity of the immunofluorescent signal for ATF6 and pIRE1 was markedly increased in the majority of busulfan-treated mice compared with the control mice $(\mathrm{P}<0.05)$. The administration of melatonin or 4PBA significantly decreased the expression levels of ATF6 and pIRE1 ( $<<0.05$, Fig. 2A-D). 


\section{Cellular Physiology Cell Physiol Biochem 2017;44:2407-2421 \begin{tabular}{ll|l} 
and Biochemistry 10.1159/000486165 & O 2017 The Author(s). Published by S. Karger AG, Basel \\
\hline
\end{tabular}

Fig. 2. Detection of ERS-related molecules in mouse testes. The expression of ERS-related molecules in mouse testes after treatment with $\mathrm{CON}, \mathrm{BU}, \mathrm{BU}+\mathrm{MEL}$ and BU+4PBA. (A, C) Representative immunofluorescent images show ATF6 expression (A) and pIRE1 (C). All images were merged from ATF6 or pIRE1 (green), PLZF (red) and Hoechst33342stained nuclei (blue). Experiments were performed in triplicate. Boxed regions of interest are enlarged and shown on the bottom line. Scale bar, $100 \mu \mathrm{m}$. (B, D) Quantitative analysis of the immunofluorescent signal for ATF6 (B) and pIRE1 (D). (E) The mRNA expression of ERS-related genes (GRP78, IRE1, XBP1 and ATF6) in testes via qRT-PCR analysis. (F) The protein expression of GRP78, IRE1, XBP1 and ATF6 in mouse testes detected by Western blot. (G) Image $\mathrm{J}$ analysis showing the mean density of the results of (F). Data are represented as the mean \pm SD $(n=3) . * P<0.05$, ** $\mathrm{P}<0.01$, and ${ }^{* * *} \mathrm{P}<0.001$.

Fig. 3. Expression of ERS-related apoptotic molecules in teste. The expression of ERS-related molecules in mouse testes after treatment with $\mathrm{CON}, \mathrm{BU}, \mathrm{BU}+\mathrm{MEL}$ and BU+4PBA. Experiments were performed in triplicate. Boxed regions of interest are enlarged and shown on the bottom line. Scale bar, $200 \mu \mathrm{m}$. (A, B) Representative immunofluorescence images (A) and their fluorescence intensity analysis (B) indicating CHOP expression. (C, D) Representative immunofluorescence images (C) and their fluorescence density analysis (D) indicating PUMA expression. (E) The testicular mRNA expression levels of CHOP, PUMA, caspase-12 and caspase- 3 were examined by qRT-PCR. (F) Western blot detection of apoptotic proteins CHOP, caspase-12, PUMA and caspase-3. (G) ImageJ analysis showing the grey value of $(\mathrm{F})$. All data are presented as the mean \pm SD $(n=3)$, and statistical significance is shown as follows: ${ }^{*} \mathrm{P}<0.05,{ }^{* *} \mathrm{P}<0.01$, and ${ }^{* * *} \mathrm{P}<0.001$.
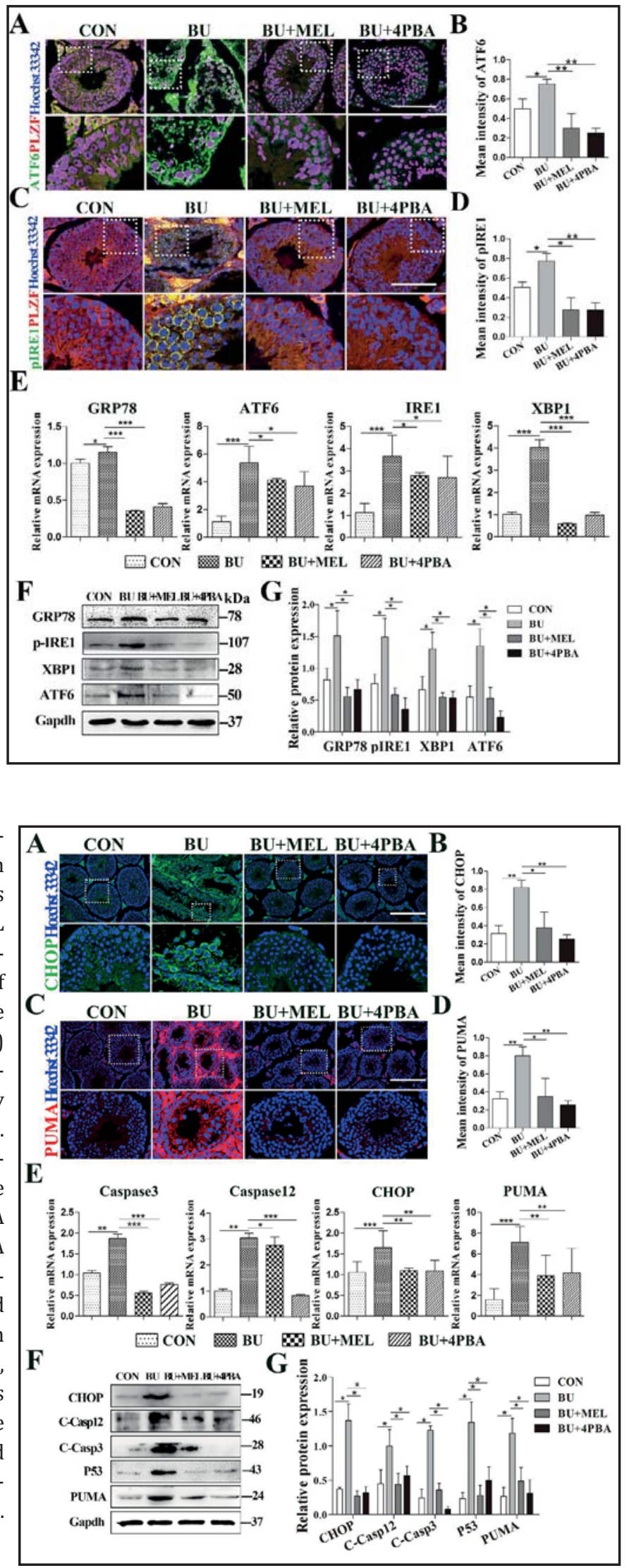


\section{Cellular Physiology Cell Physiol Biochem 2017;44:2407-2421 \begin{tabular}{c|l|l} 
DOI: 10.1159/000486165 & @ 2017 The Author(s). Published by S. Karger AG, Basel \\
www.karger.com/cpb
\end{tabular}}

Cui et al.: Melatonin Relieves Busulfan-Induced Testis Damage

We also assessed the expression levels of ERS-related genes in the testes through qRTPCR. Compared with that in the control group, the mRNA expression of GRP78, Atf6, pIRE1, and Xbp1 in the busulfan-treated group was significantly increased (0.14-, 2.26-, 2.99-, and 3.79-fold increases compared with the control group, respectively, $\mathrm{P}<0.05$ ). However, this increasing trend was significantly reversed when the treatment was combined with melatonin or 4PBA ( $\mathrm{P}<0.05$, Fig. 2E).

Western blotting was applied to examine the effect of ERS activation. In the control group, a low and basal activation level of the ERS-related proteins was detected. After busulfan was added, the expression of GRP78, pIRE1, XBP1, and ATF6 was clearly stimulated. In the presence of melatonin or 4PBA, the activation effect was reversed $(\mathrm{P}<0.05$, Fig. $2 \mathrm{~F}-\mathrm{G})$. Therefore, melatonin protected the testes from ERS damage.

Melatonin suppressed the expression of ERS-related apoptotic genes in testes

To evaluate the protectivemechanism of melatonin, weinvestigated the protein expression of the ERS-related apoptotic genes CHOP and PUMA through an immunofluorescence assay. CHOP had a high level of expression after busulfan treatment but low expression in the melatonin- and 4PBA-treated groups ( $\mathrm{P}<0.05$, Fig. 3A-B). Compared to control mice, intense fluorescent signals of PUMA were found in the busulfan-treated group. Conversely, weak signals were observed in the melatonin- and 4PBA-treated groups $(\mathrm{P}<0.05$, Fig. 3CD). The mRNA expression levels of CHOP, PUMA, caspase- 3 and caspase- 12 were examined through qRT-PCR analysis, and similar to the immunofluorescence analysis, the mRNA expression level of ERS-related apoptotic genes was increased relative to the control group after busulfan was administered, whereas the increase was significantly compromised by melatonin or 4PBA ( $P<0.05$, Fig. 3E).

Western blotting results further revealed that co-administration of busulfan with melatonin or 4PBA significantly downregulated the expression of the ERS-mediated apoptosis

Fig. 4. Expression of melatonin receptors MT1 and MT2. The expression of MT1 and MT2 in mouse testes or C18-4 after treatment with $\mathrm{CON}, \mathrm{BU}, \mathrm{BU}+\mathrm{MEL}$ and BU+4PBA. (A) Immunofluorescent assay for MT1 in C18-4 cells. Scale bar, $200 \mu \mathrm{m}$. (B) Quantitation analysis of MT1-positive cells in A. (C) Immunofluorescent assay of MT2 in C18-4 cells. Boxed regions of interest are enlarged and shown on the bottom line. Scale bar, $200 \mu \mathrm{m}$. (D) Quantitation analysis of MT1-positive cells in C. (E) Immunofluorescent assay of MT1 and MT2 in mouse testes with different treatments. Scale bar, $100 \mu \mathrm{m}$. (F) Quantitation of mean immunofluorescent density signals for MT1 and MT2 in E. (G) Western blot analysis of MT1 and MT2 in C18-4 cells. (H) Image J analysis showing the grey value of $(G)$. All experiments were performed in triplicate. Data are presented as the mean $\pm \operatorname{SD}(n=3)$. Statistical significance is expressed as follows: *

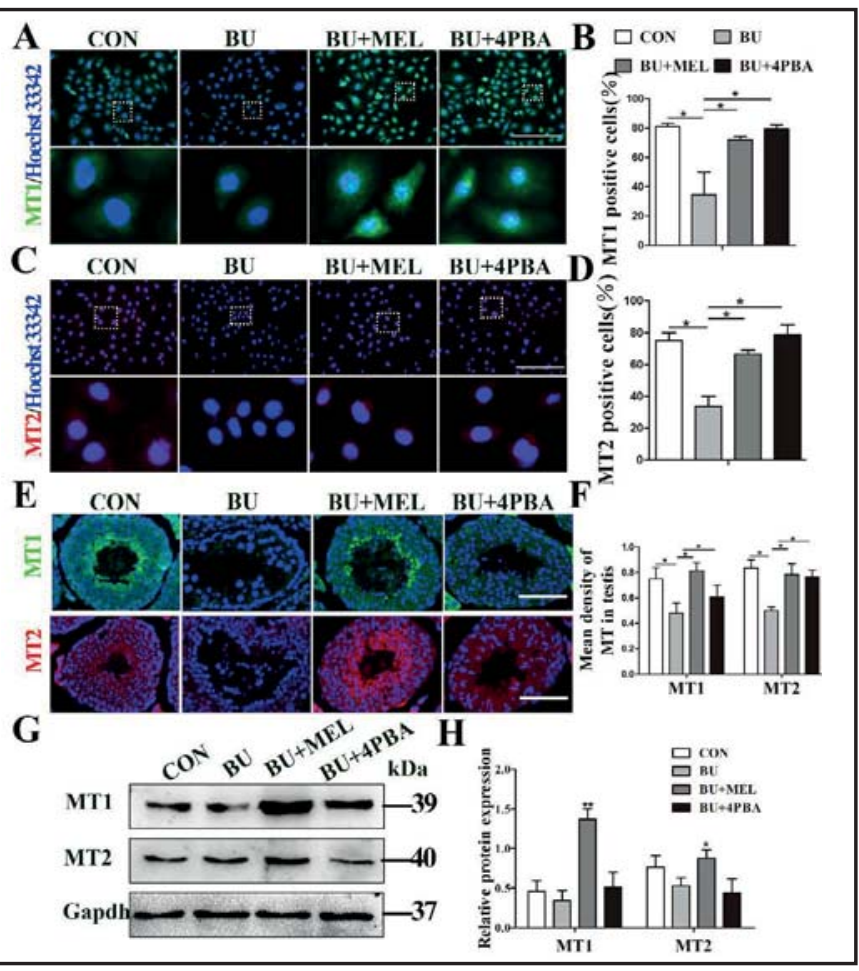
$\mathrm{P}<0.05$, ** $\mathrm{P}<0.01$, and ${ }^{* * *} \mathrm{P}<0.001$. 


\section{Cellular Physiology Cell Physiol Biochem 2017:44:2407-2421 \begin{tabular}{c|l|l} 
DOI: 10.1159/000486165 & $\begin{array}{l}\text { ( ) } 2017 \text { The Author(s). Published by S. Karger AG, Basel } \\
\text { www.karger.com/cpb }\end{array}$
\end{tabular}}

Cui et al.: Melatonin Relieves Busulfan-Induced Testis Damage

protein CHOP, cleaved caspase-12, PUMA, and cleaved caspase-3, all of which were upregulated by busulfan $(P<0.05$, Fig. 3F-G). Therefore, ERS might be activated by busulfan and act to further induce testicular cell apoptosis and spermatogonium loss. The combined treatment with melatonin abolished the adverse effects of busulfan on the testes.

Melatonin increased MT1 and MT2 expression levels

To evaluate the importance of melatonin receptors (MT) in facilitating the therapeutic functions of melatonin, we performed an immunofluorescence analysis of melatonin receptors in the testes and mouse SSCs. The untreated cells showed normal signals of MT1 and MT2. However, only weak signals were found in busulfan-treated cells. In contrast, the fluorescent signals of MT1 and MT2 were highly enriched in melatonin- and 4PBA-treated cells (Fig. 4A-C). The quantitative results of the immunofluorescence assay showed that the positive signals were weaker in the busulfan-treated group than in the control cells. The fluorescent signals of MT1 and MT2 were enhanced when melatonin was administered compared with the busulfan-treated group. Moreover, 4PBA treatment increased the signals of MT1 and MT2 ( $<0.05$, Fig. 4B-D). Similar to cell immunofluorescence

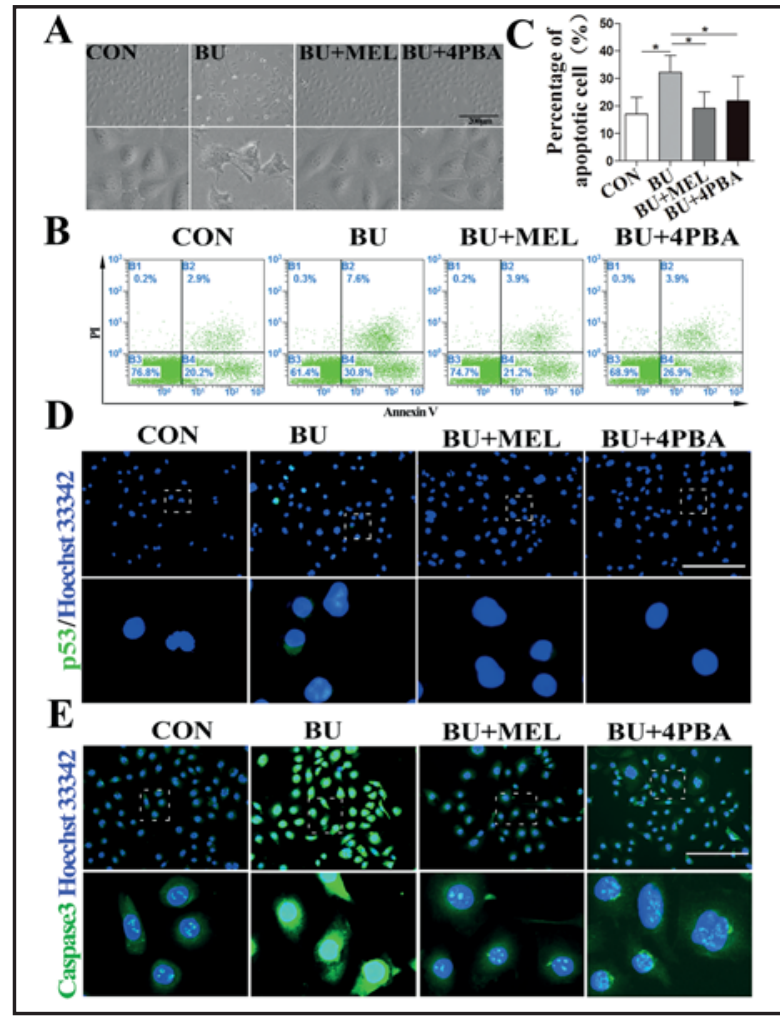

Fig. 5. Effect of melatonin on the apoptosis of C18-4 cells. (A) The morphological changes of C18-4 cells after different treatments. The images are representative of at least three independent experiments. (B) The apoptosis of C18-4 cells was examined by flow cytometry analysis. (C) Percentages of the apoptotic cells that were analysed in B. (D) Immunofluorescent assay of P53. (E) Immunofluorescent assay of cleaved caspase 3. The images are representative of at least three independent experiments. Boxed regions of interest are enlarged and shown on the bottom line. Scale bar, $200 \mu \mathrm{m}$. Mean \pm SD was calculated from at least three determinations. ${ }^{*} \mathrm{P}<0.05$. analysis, testicular fluorescence analysis revealed that intense MT1 and MT2 fluorescent signals were observed in melatoninor 4PBA-treated testes; however, weak signals were found in the seminiferous tubules of the testes treated with busulfan (Fig. 4E). The quantitation results confirmed that the MT1 and MT2 expression levels were increased in the melatonin-treated group compared with the busulfan-treated group. 4PBA administration increased MT1 and MT2 expression compared with that of the busulfan group $(P<0.05$, Fig. 4F). Western blotting further confirmed that administration of melatonin significantly upregulated the expression of MT1 and MT2 (P < 0.05 , Fig. $4 \mathrm{G}-\mathrm{H}$ ). These data suggested that the protective role of melatonin against mouse testicular damage was mediated by MT1 and MT2.

\section{Melatonin inhibited mouse SSC apoptosis}

The mouse C18-4 cell line, which is a type A SSC, was examined to verify the direct effects of melatonin and busulfan on spermatogonial cells. To confirm the involvement of ERS, we co-treated the cells with 4PBA. Co-treatment with melatonin was also administered to assess the role of melatonin in busulfan-induced apoptosis. After treatment with busulfan, the morphological characteristics of the C18-4 cells were shrunken, and their surface was 


\section{Cellular Physiology \\ Cell Physiol Biochem 2017:44:2407-2421

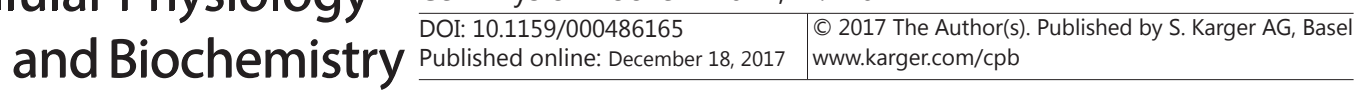

Cui et al.: Melatonin Relieves Busulfan-Induced Testis Damage

rough in comparison to the control cells, as revealed by light microscopy. Conversely, the co-administration of melatonin or 4PBA significantly reversed these morphological changes (Fig. 5A). We counted the number of annexin $\mathrm{V}$ FITC-positive cells through flow cytometry analysis. Compared to the control group, busulfan treatment increased the percentage of apoptotic cells; however, the administration of melatonin or 4PBA decreased the percentage of apoptotic cells compared with the busulfan-treated cells (P $<0.05$, Fig. 5B-C). To confirm these results, we analysed the apoptotic proteins P53 and cleaved caspase-3 through immunofluorescence assay. Intense fluorescent signals indicating the presence of apoptosis were observed in the busulfan-treated cells. Conversely, only slight fluorescence was detected in the melatonin- and 4PBA-treated cells (Fig. 5D-E). These exper-

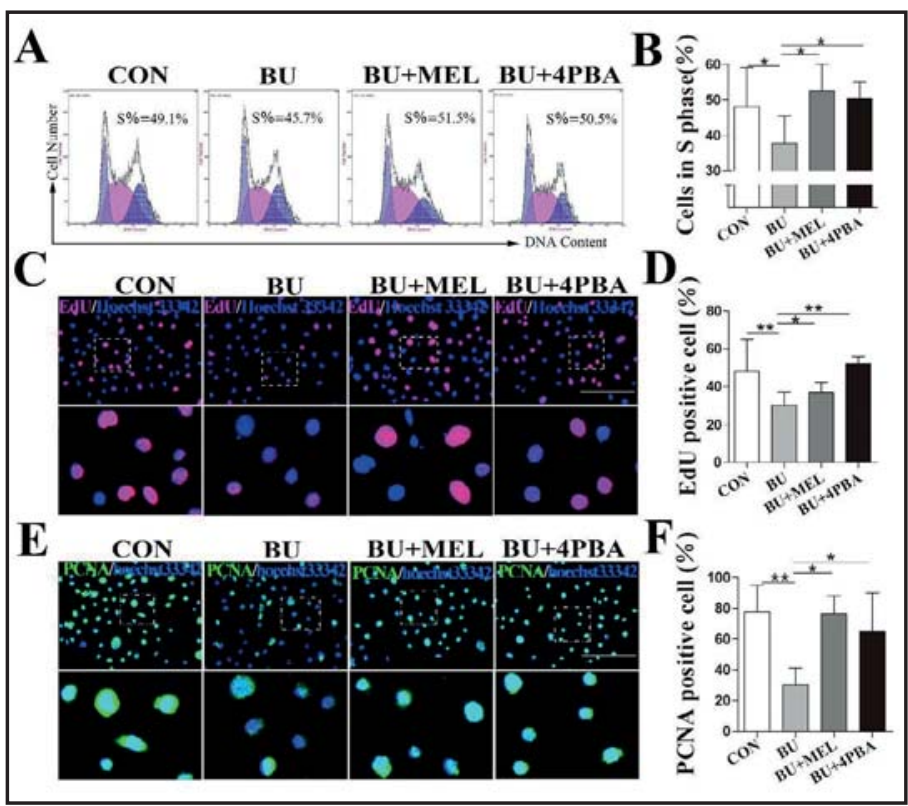

Fig. 6. Effect of melatonin on the proliferation of C18-4 cells. (A) The cell cycle proportions of C18-4 cells detected by flow cytometry. (B) The percentage of C18-4 cells in S phase. (C) Representative images of the EdU assay in C18-4 cells in different treatment groups. Scale bar, $200 \mu \mathrm{m}$. (D) EdU-positive rate of C18-4 cells. (E) Immunofluorescent assay of proliferative protein PCNA. Scale bar, $200 \mu \mathrm{m}$. (F) Percentage of PCNA positive cells in different treatment groups were counted. All experiments were repeated at least three times. Boxed regions of interest are enlarged and shown on the bottom line. Scale bar, $200 \mu \mathrm{m}$. Data are presented as the mean \pm SD $(n=3)$, and statistical significance is expressed as follows: $* \mathrm{P}<0.05$ and ${ }^{* *} \mathrm{P}<0.01$. iments suggested that melatonin treatment could sufficiently enhance the resistance of mouse SSCs to busulfan-induced apoptosis.

\section{Melatonin promoted mouse SSC proliferation}

Cell cycle distribution was measured to explore the effects of melatonin and busulfan on the proliferation of mouse SSCs. Our results indicated that the percentage of busulfantreated cells in the S phase was reduced compared with the control group. In contrast, the percentage of S-phase cells increased in the melatonin- and 4PBA-treated cells $(\mathrm{P}<0.05$, Fig. 6A-B). Cell proliferation was observed by using the EdU kit. The cell proliferation rate was reduced in the busulfan treatment group compared with that of the control group (18.5 $\pm 9 \%, \mathrm{P}<0.05$ ). Conversely, melatonin promoted the proliferation activity of mouse SSCs. Compared with the busulfan-treated group, the proliferation of the SSCs was increased in the 4PBA-treated group $(\mathrm{P}<0.05$, Fig. $6 \mathrm{C}-\mathrm{D})$. To confirm these results, we analysed the proliferative protein PCNA through immunofluorescence assay and found that the number of positive cells was reduced in the busulfan-treated group relative to the control cells $(\mathrm{P}<$ 0.05). In contrast, the percentage of PCNA-positive cells in the melatonin- and 4PBA-treated group increased $(\mathrm{P}<0.05$, Fig. $6 \mathrm{E}-\mathrm{F})$. These data suggest that melatonin may promote SSC survival and drive their proliferation to promote regeneration after busulfan treatment.

Melatonin inhibited ERS activation in mouse SSCs

C18-4 cells were examined through immunofluorescence assays to clarify whether spermatogenic cells treated with busulfan in vitro induced ERS and to determine the effect 


\section{Cellular Physiology Cell Physiol Biochem 2017;44:2407-2421 \begin{tabular}{c|l|l} 
DOI: 10.1159/000486165 & (c) 2017 The Author(s). Published by S. Karger AG, Basel \\
www.karger.com/cpb
\end{tabular}}

Cui et al.: Melatonin Relieves Busulfan-Induced Testis Damage

of melatonin on the expression of ERS-related molecules. The ERS indicator ATF6 had a high level of expression in the busulfan group but low expression in melatonin- and 4PBA-treated cells $(\mathrm{P}<0.05$, Fig. 7A, D). Cell imaging revealed that the pIRE1 signals were enhanced in the busulfan group relative to the control group. In comparison, this strong signal was suppressed by either melatonin or 4PBA ( $\mathrm{P}<0.05$, Fig. 7B, E). Intense fluorescent signals of pPERK indicated that higher ERS levels occurred in the busulfan-treated cells than in the control group. Conversely, low levels of fluorescence showed that the ERS level was reduced in melatonin- and 4PBA-treated cells compared with the busulfan treatment group $(\mathrm{P}<0.05$, Fig. 7C, F). We also measured intracellular $\mathrm{Ca}^{2+}$ levels through Fluo-3AM staining because ER is a major calcium-storage organelle, and its calcium content is essential for proper protein folding and transport. The disruption of calcium homeostasis can disturb ER functions and induce ERS [31]. Our results indicated that the intracellular $\mathrm{Ca}^{2+}$ concentration increased in C18-4 cells treated with busulfan. Conversely, the co-treatment of busulfan with melatonin or 4PBA failed to increase intracellular $\mathrm{Ca}^{2+}$ levels (Fig. 7G). Therefore, busulfan enhanced the activation of ERS in C18-4 cells, but co-treatment with melatonin resulted in improved ER homeostasis.

\section{Melatonin counteracted ERS-related apoptosis in mouse SSCS}

To obtain insights into the mechanism by which busulfan induces apoptosis and to clarify whether melatonin prevents apoptosis caused by ERS in mouse SSCs, we performed immunofluorescence analysis. The results demonstrated that the signals from the ERSrelated apoptotic marker cleaved caspase- 12 were enhanced in the busulfan-treated cells compared with the control cells. In contrast, a relatively weak fluorescence signal was detected in the cells treated with busulfan combined with melatonin or 4PBA $(\mathrm{P}<0.05$, Fig. $8 \mathrm{~A}-\mathrm{B}$ ). The quantitative results of the immunofluorescence assay of whole cells revealed that the CHOP expression level was increased in the busulfan-treated cells relative to the control cells. Conversely, the signal was suppressed when the cells were co-treated with melatonin or 4PBA (P $<0.05$, Fig. 8C-D).

We also investigated PUMA expression, which is reported to be a proapoptotic gene induced by ERS [32]. Our results showed that melatonin suppressed PUMA expression

Fig. 7. Expression of ERS-related proteins in C18-4 cells. The C18-4 cells were treated with $\mathrm{CON}, \mathrm{BU}$, BU+MEL and BU+4PBA. The expression of ERS-related proteins and the intracellular $\mathrm{Ca}^{2+}$ level in C18-4 was detected. (A-C) Immunofluorescence images of ERS indicators ATF6 (A), pIRE1 (B) and pPERK (C) in C18-4 cells. Scale bar, $100 \mu \mathrm{m}$. (D-F) Immunofluorescence images of pIRE1 in C18-4 cells. Scale bar, $100 \mu \mathrm{m}$. (D) Statistical analysis of the positive rate of ATF6 (D), pIRE1 (E) and pPERK (F). (G) Analysis of the intracellular $\mathrm{Ca}^{2+}$ level was measured by flow cytometry. Experiments were performed in triplicate. All data are presented as the mean \pm SD $(n=3)$. Statistical significance is expressed as follows: ${ }^{*} \mathrm{P}<0.05$ and ${ }^{* *} \mathrm{P}<0.01$.

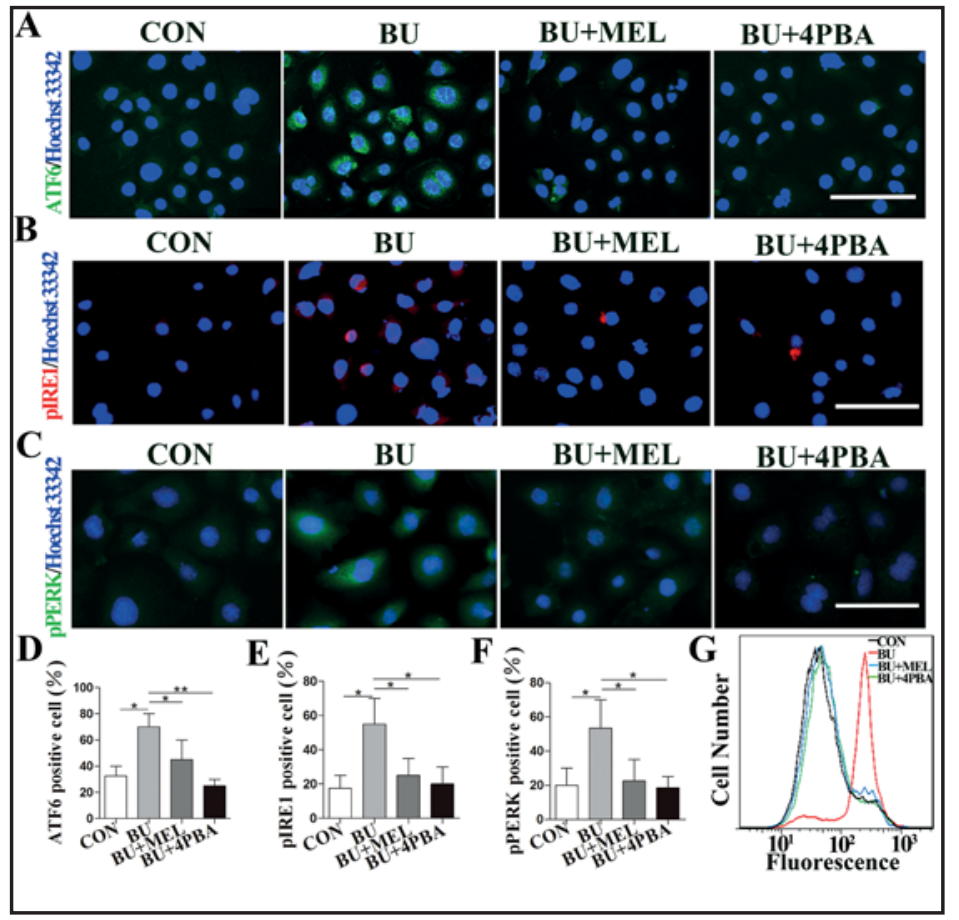




\section{Cellular Physiology \\ Cell Physiol Biochem 2017;44:2407-2421 \\ \begin{tabular}{ll|l} 
and Biochemistry $10.1159 / 000486165$ & Published online: December 18, 2017 & $\begin{array}{l}\text { 2017 The Author(s). Published by S. Karger AG, Basel } \\
\text { www.karger.com/cpb }\end{array}$ \\
\hline
\end{tabular}}

Cui et al.: Melatonin Relieves Busulfan-Induced Testis Damage

Fig. 8. Expression of ERS-related apoptosis markers in C18-4 cells. (A, B) Representative immunofluorescence images (A) and positive rate analysis (B) of caspase-12 in C18-4 cells. (C, D) Representative immunofluorescence images (C) and positive rate analysis (D) of CHOP in C18-4 cells. (E, F) Representative immunofluorescence images (E) and positive rate analysis (F) of PUMA in C18-4 cells. Boxed regions of interest are enlarged and shown on the bottom line. Scale bar, $200 \mu \mathrm{m}$. Data are presented as the mean \pm SD of three separate determinations. Statistical significance was indicated as follows: ${ }^{*} \mathrm{P}<0.05$ and ${ }^{* *} \mathrm{P}<0.01$.

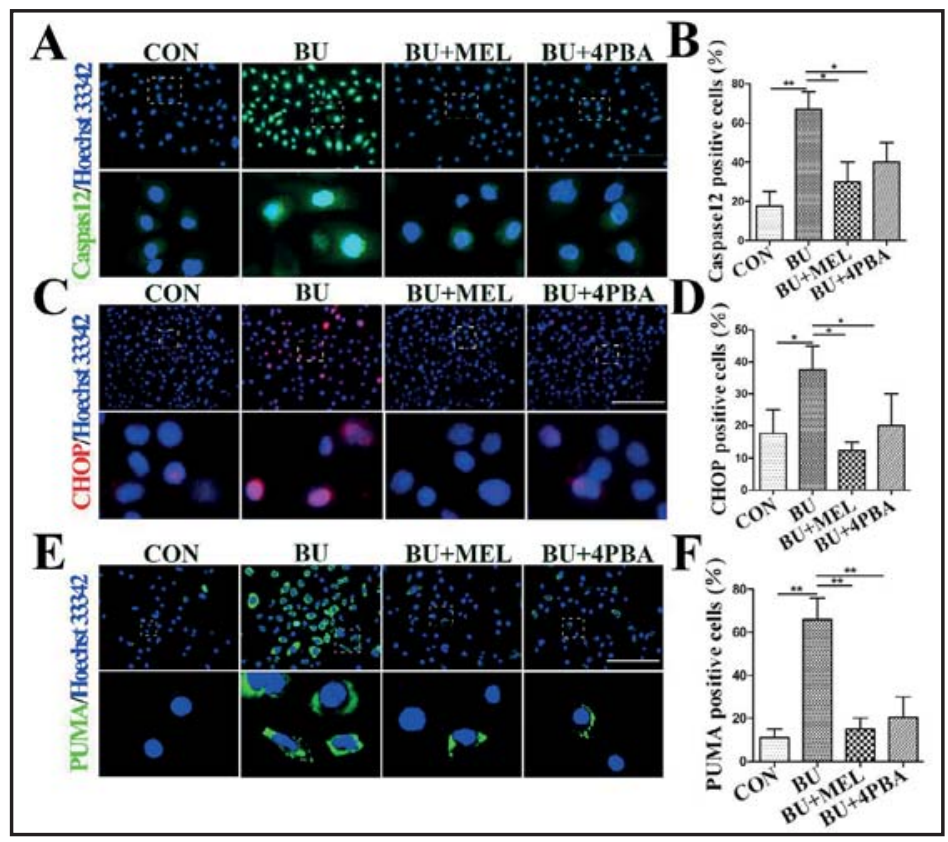

stimulated by busulfan ( $\mathrm{P}<0.05$, Fig. 8E-F). From these results, we conclude that mouse SSCs exposed to busulfan undergo ERS-related apoptosis, but in contrast, cells co-administered melatonin or 4PBA conferred higher resistance than busulfan-treated cells.

\section{Discussion}

Chemotherapeutic drugs, such as busulfan, are often used to treat cancer and increase the survival rates of patients. However, these chemotherapeutics may induce temporary or permanent reproductive toxicity in male patients. Children and adolescents with testicular cancer or leukaemia are at high risk of developing permanent sterility because of chemotherapeutic application. Therefore, strategies that effectively preserve fertility during the course of cancer treatment should be developed [33, 34]. In this study, we provide evidence that melatonin is sufficient to counteract busulfan-induced testicular damage and SSC apoptosis. Moreover, we found that the protective effect of melatonin is dependent on ERS alleviation.

The ER is an important organelle involved in protein folding, calcium homeostasis maintenance, and lipid biosynthesis [35]. ERS occurs when unfolded proteins accumulate and the folding capacity of ER chaperones exceeds the capacity of the ER lumen to facilitate their disposal. It is a major contributor to various diseases, such as cancer, diabetes and Alzheimer's disease [36, 37]. As such, targeting the components of the ERS signal pathway has been widely explored as a therapeutic strategy [38].

Despite a large number of studies linking ERS to toxicants, currently, studies have yet to determine whether ERS is a contributing factor to busulfan-induced testicular damage and apoptosis $[39,40]$. In this study, we demonstrated the relationship between testicular damage and ERS pathways in response to busulfan. We evaluated ERS-related genes and found an increased expression of GRP78, ATF6, pIRE1, and XBP1 in busulfan-treated mouse testes. This finding suggested that ERS could be responsible for busulfan-induced testicular damage. A recent report showed that activation of ATF4 and CHOP could enhance protein synthesis and subsequently induce ERS and apoptosis [41]. Our results further demonstrated that busulfan treatment increased the expression of ERS-related apoptotic proteins, such as CHOP and cleaved caspase-12. We also found an increase in P53 and PUMA protein levels in response to busulfan treatment, which could be further confirmed by evaluating levels 


\section{Cellular Physiology Cell Physiol Biochem 2017;44:2407-2421

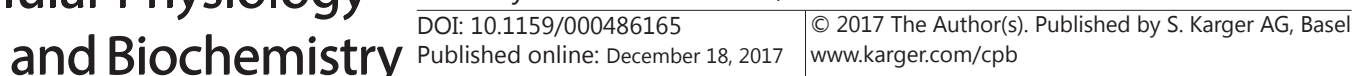

Cui et al.: Melatonin Relieves Busulfan-Induced Testis Damage

of apoptosis because P53 acts as a transcription factor that regulates the expression of apoptosis-related genes [42], and PUMA is a potent pro-apoptotic protein because of its ability to bind and neutralize all pro-survival BCL2 members [43]. Therefore, ERS regulation could involve apoptotic actions in testicular damage. Our experiments on mouse SSCs were consistent with that on the mouse testes. These findings (both in vitro and in vivo) suggest that inhibition of ERS might be a target of novel therapeutics for male infertility.

Melatonin and its metabolites are well-known broad-spectrum antioxidants and free radical scavengers that regulate various molecular pathways, such as inflammation, proliferation, apoptosis, and metastasis, during different pathological conditions [44-46]. It has been documented that melatonin modulates the signalling of neuronal cell death [47] and bladder cancer cells induced by ERS [48]. Melatonin significantly reverses tunicamycininduced ERS in human hepatocellular carcinoma cells and improves cytotoxic responses to doxorubicin by increasing the expression of CHOP [49]. A couple of studies revealed that melatonin alleviates Cd-induced cellular stress and germ cell apoptosis in testes [50] and prevents bisphenol A-induced apoptosis by controlling BCL2 expression and ameliorating oxidative stress in the testes and sperm [51]. Furthermore, melatonin had a positive influence on the efficiency of male germ cell differentiation [52], and it can promote goat SSC proliferation by stimulating GDNF production in Sertoli cells [53].

Similarly, our data showed that melatonin contributed to the proliferation of mouse SSCs, but the proliferation was suppressed when they were exposed to busulfan. Indeed, our recent study has shown that melatonin markedly reduces the extent of testicular injury by inhibiting oxidative stress [28]. However, whether melatonin could relieve busulfan-induced ERS in testes and SSCs was previously unclear. Here, we showed that melatonin significantly alleviated busulfan-induced testicular ERS by suppressing the expression levels of the key ERS genes pIRE1 and ATF6 and inhibiting the ERS-related apoptotic genes CHOP and caspase-12. Moreover, the integrity of the testes was significantly preserved by melatonin treatment. Previous studies reported that the effects of melatonin were mediated by the specific receptors MT1 and MT2 [54]. Melatonin pretreatment inhibited the activating role of tunicamycin on ERS through melatonin receptor-mediated IRE-1 signalling in skeletal muscle cells [55]. Similarly, our study suggests that the expression of MT1 and MT2 was increased in exogenous melatonin-treated mouse testes and SSCs, and these findings imply that the protective role of melatonin against mouse testicular damage could be exerted through MT1 and MT2.

4PBA is known to be a major repressor of ERS by improving the folding capacity of misfolded proteins [30]. It is capable of counteracting the toxic effect of proteinuria through suppressing ATF4 and attenuating ERS in chronic kidney disease [56]. To elucidate the mechanism behind the inhibition of ERS by melatonin, 4PBA was utilized. We found that the expression of ERS-related genes and apoptosis genes decreased to normal levels when 4PBA was co-administered with busulfan. Similar to 4BPA, melatonin is able to protect against cerebral IR injury through inhibiting ERS via PERK and IRE1 signals [57]. Downregulation of

Fig. 9. Schema diagram illustrating the mechanism of how melatonin blocked busulfan-induced spermatogonial stem cell apoptosis in mouse testes.

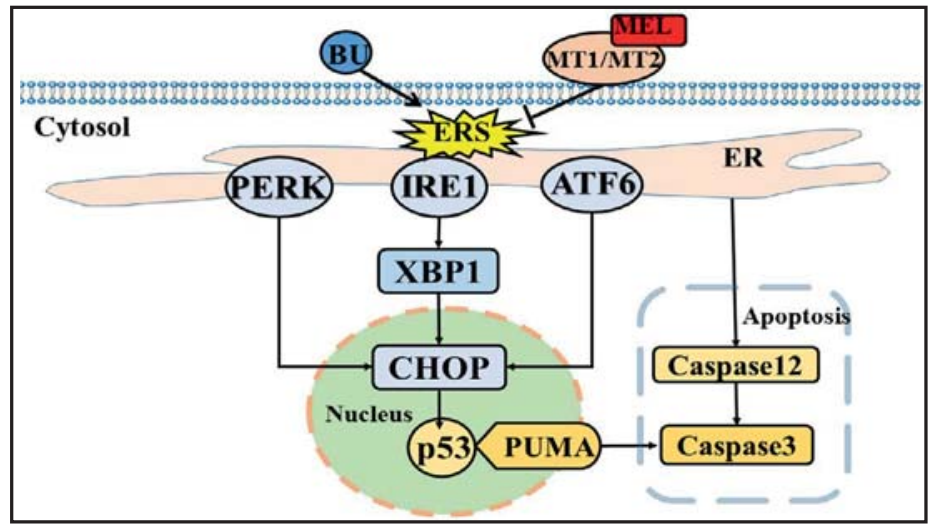




\section{Cellular Physiology Cell Physiol Biochem 2017;44:2407-2421 \begin{tabular}{ll|l} 
and Biochemistry 10.1159/000486165 & $\begin{array}{l}\text { O 2017 The Author(s). Published by S. Karger AG, Basel } \\
\text { www.karger.com/cpb }\end{array}$
\end{tabular} \\ Cui et al.: Melatonin Relieves Busulfan-Induced Testis Damage}

ATF- 6 by melatonin contributes to ERS-induced apoptosis of human hepatoma cells [58]. In the current study, we found that melatonin could abrogate busulfan-induced ERS in mouse SSCs by inhibiting the ERS-related genes IRE1 and PERK, which further depressed pro-apoptotic transcript CHOP activation, then inhibited P53 expression and resulted in the reduction of PUMA, and consequently decreased the accumulation of cellular caspase, thereby preventing cell apoptosis (Fig. 9). Thus, we conclude that melatonin treatment significantly protected mouse SSCs from busulfan-induced apoptosis and protected testes from damage in busulfan-treated mice. This study suggests that melatonin could provide potential therapeutic advantages by protecting the testes from busulfan-induced injury.

Taken together, our study demonstrated that the activation of ERS signalling contributed to busulfan-induced SSC apoptosis and that melatonin treatment significantly protected mouse SSCs from busulfan-induced apoptosis. This study provides basic information that helps us to understand the recovery of spermatogenesis in men after cancer treatment and provides guidance about the possible effects that new agents might have on the testes of male patients with cancer.

\section{Acknowledgements}

This work was supported by grants from the National Key Research and Development Program of China (2016YFA0100203 and 2016YFD0500306), the General Programs of Natural Science Foundation of China (31572399, 31272518), and the Key Project of Shaanxi Province of Science and Technology (2015NY157).

\section{Disclosure Statement}

The authors declare no conflicts of interest.

\section{References}

1 Wlc H, Bourne H, Gook D, Clarke G, Kemertzis M, Stern K, Agresta F, Heloury Y, Clarke H, Orme L: A short report on current fertility preservation strategies for boys. Clin Endocrinol 2017;87:279-285.

$\longrightarrow 2$ Meistrich ML: Effects of chemotherapy and radiotherapy on spermatogenesis in humans. Fertil Steril 2013;100:1180-1186.

3 Levine JM, Kelvin JF, Quinn GP, Gracia CR: Infertility in reproductive-age female cancer survivors. CancerAm Cancer Soc 2015;121:1532-1539.

4 Kotzur T, Benavidesgarcia R, Mecklenburg J, Sanchez JR, Reilly M, Hermann BP: Granulocyte colonystimulating factor (g-csf) promotes spermatogenic regeneration from surviving spermatogonia after highdose alkylating chemotherapy. Reprod Biol Endocrinol DOI: 10.1186/s12958-016-0226-1.

5 Brignardello E, Felicetti F, Castiglione A, Nervo A, Biasin E, Ciccone G, Fagioli F, Corrias A: Gonadal status in long-term male survivors of childhood cancer. J Cancer Res Clin 2016;142:1-6.

6 Nasimi P, Vahdati A, Tabandeh MR, Khatamsaz S: Cytoprotective and anti-apoptotic effects of satureja khuzestanica essential oil against busulfan-mediated sperm damage and seminiferous tubules destruction in adult male mice. Andrologia 2016;48:74-81.

-7 Ceribaşi AO, Türk G, Sönmez M, Sakin F, Ateşşahin A: Toxic effect of cyclophosphamide on sperm morphology, testicular histology and blood oxidant-antioxidant balance, and protective roles of lycopene and ellagic acid. Basic Clin Pharmacol 2010;107:730-736.

$>8$ Wang S, Kaufman RJ: The impact of the unfolded protein response on human disease. J Cell Biol 2012;197:857-867.

9 Wang M, Kaufman RJ: Protein misfolding in the endoplasmic reticulum as a conduit to human disease. Nature 2016;529:326-335.

10 Walter P, Ron D: The unfolded protein response: from stress pathway to homeostatic regulation. Science 2011;334:1081-1086.

11 Seo J, Rd FE, Suh JM, Stenesen D, Tang W, Parks EJ, Adams CM, Townes T, Graff JM: Atf4 regulates obesity, glucose homeostasis, and energy expenditure. Diabetes 2009;58:2565-2573.

12 Hetz C, Mollereau B: Disturbance of endoplasmic reticulum proteostasis in neurodegenerative diseases. Nat Rev Neurosci 2014;15:233-249. 


\section{Cellular Physiology Cell Physiol Biochem 2017;44:2407-2421 \begin{tabular}{l|l|l} 
DOI: 10.1159/000486165 & (c) 2017 The Author(s). Published by S. Karger AG, Base
\end{tabular}

13 Baleriola J, Walker CA, Jean YY, Crary JF, Troy CM, Nagy PL, Hengst U: Axonally synthesized atf4 transmits a neurodegenerative signal across brain regions. Cell 2014;158:1159-1172.

14 Li K, Zhang J, Yu J, Liu B, Guo Y, Deng J, Chen S, Wang C, Guo F: Microrna-214 suppresses gluconeogenesis by targeting activating transcriptional factor 4. J Biol Chem 2015;290:8185-8195.

-15 Tavernier SJ, Osorio F, Vandersarren L, Vetters J, Vanlangenakker N, Van Isterdael G, Vergote K, De Rycke R, Parthoens E, van de Laar L: Regulated ire1-dependent mrna decay sets the threshold for dendritic cell survival. Nat Cell Biol 2017;19:698-710.

-16 Jin J, Blackwood EA, Azizi KM, Thuerauf DJ, Fahem AG, Hofmann C, Kaufman RJ, Doroudgar S, Glembotski CC: Atf6 decreases myocardial ischemia/reperfusion damage and links er stress and oxidative stress signaling pathways in the heart. Circ Res 2017;120:862-875.

-17 Jiang M, Liu L, He X, Wang H, Lin W, Wang H, Yoon SO, Wood TL, Lu QR: Regulation of PERK-eIF2 $\alpha$ signalling by tuberous sclerosis complex- 1 controls homoeostasis and survival of myelinating oligodendrocytes DOI: 10.1038/ncomms13767.

-18 Liu H, Van DWB, Sillence C, Nagelkerke JF, Stevens JL: Endoplasmic reticulum chaperones grp78 and calreticulin prevent oxidative stress, $\mathrm{ca}^{2+}$ disturbances, and cell death in renal epithelial cells. J Biol Chem 1997;272:21751-21759.

19 Castle-Miller J, Bates DO, Tortonese DJ: Mechanisms regulating angiogenesis underlie seasonal control of pituitary function. Proc Natl Acad Sci USA 2017;114:E2514-E2523.

20 Yang Y, Sun Y, Yi W, Li Y, Fan C, Xin Z, Jiang S, Di S, Qu Y, Reiter RJ: A review of melatonin as a suitable antioxidant against myocardial ischemia-reperfusion injury and clinical heart diseases. J Pineal Res 2014;57:357-366.

21 Janjetovic Z, Jarrett SG, Lee EF, Duprey C, Reiter RJ, Slominski AT: Melatonin and its metabolites protect human melanocytes against uvb-induced damage: involvement of nrf2-mediated pathways. Sci Rep-Uk DOI: 10.1038/s41598-017-01305-2.

-22 Ramos E, Patiño P, Reiter RJ, Gil-Martín E, Marco-Contelles J, Parada E, Los RC, Romero A, Egea J: Ischemic brain injury: new insights on the protective role of melatonin. Free Radic Biol Med 2017;104:32-53.

-23 Hu W, Ma Z, Di S, Jiang S, Li Y, Fan C, Yang Y, Wang D: Snapshot: implications of melatonin in endoplasmic reticulum homeostasis. Brit J Pharmacol 2016;173:3431-3442

-24 Moreira AJ, Ordoñez R, Cerski CT, Picada JN, Garcíapalomo A, Marroni NP, Mauriz JL, Gonzálezgallego J: Melatonin activates endoplasmic reticulum stress and apoptosis in rats with diethylnitrosamine-induced hepatocarcinogenesis. Plos One DOI: 10.1371/journal.pone.0144517.

-25 Zhao H, Wu QQ Cao LF, Qing HY, Zhang C, Chen YH, Wang H, Liu RR, Xu DX: Melatonin inhibits endoplasmic reticulum stress and epithelial-mesenchymal transition during bleomycin-induced pulmonary fibrosis in mice. Plos One DOI: 10.1371/journal.pone.0097266.

26 Li C, Zhou X: Melatonin and male reproduction. Clin Chim Acta 2015;446:175-180.

27 Jang H, Lee OH, Lee Y, Yoon H, Chang EM, Park M, Lee JW, Hong K, Kim JO, Kim NK: Melatonin prevents cisplatin-induced primordial follicle loss via suppression of pten/akt/foxo3a pathway activation in the mouse ovary. J Pineal Res 2016;60:336-347.

28 Li B, He X, Zhuang M, Niu B, Wu C, Mu H, Tang F, Cui Y, Liu W, Zhao B: Melatonin ameliorates busulfaninduced spermatogonial stem cell oxidative apoptosis in mouse testes. Antioxid Redox Sign DOI: 10.1089/ ars.2016.6792.

29 Zheng L, Zhu H, Mu H, Wu J, Song W, Zhai Y, Peng S, Li G, Hua J: Cd49f promotes proliferation of male dairy goat germline stem cells. Cell Prolif 2016;49:27-35.

-30 Gioia R, Tonelli F, Ceppi I, Biggiogera M, Leikin S, Fisher S, Tenedini E, Yorgan TA, Schinke T, Tian K: The chaperone activity of $4 \mathrm{pba}$ ameliorates the skeletal phenotype of chihuahua, a zebrafish model for dominant osteogenesis imperfecta. Hum Mol Genet 2017;26:2897-2911.

-31 Pauly M, Angebaultprouteau C, Dridi H, Notarnicola C, Scheuermann V, Lacampagne A, Matecki S, Fauconnier J: ER stress disturbs sr/er-mitochondria $\mathrm{ca}^{2+}$ transfer: implications in duchenne muscular dystrophy. Biochim Biophys Acta 2017;1863:2229-2239.

-32 Glab JA, Doerflinger M, Nedeva C, Jose I, Mbogo GW, Paton JC, Paton AW, Kueh AJ, Herold MJ, Huang DC: DR5 and caspase-8 are dispensable in ER stress-induced apoptosis. Cell Death Differ 2017;24:944-950.

-33 Tournaye H, Dohle GR, Barratt CL: Fertility preservation in men with cancer. J Reprod Med 2012;107:92909297.

- 34 Hsiao W, Stahl PJ, Osterberg EC, Nejat E, Palermo GD, Rosenwaks Z, Schlegel PN: Successful treatment of postchemotherapy azoospermia with microsurgical testicular sperm extraction: the weill cornell experience. J Clin Oncol 2011;29:1607-1611.

-35 Senft D, Ronai ZEA: Upr, autophagy and mitochondria crosstalk underlies the ER stress response. Trends Biochem Sci 2015;40:141-148. 


\section{Cellular Physiology Cell Physiol Biochem 2017;44:2407-2421 \begin{tabular}{l|l|l} 
DOI: 10.1159/000486165 & (c) 2017 The Author(s). Published by S. Karger AG, Base
\end{tabular}

-36 Wang M, Kaufman RJ: Protein misfolding in the endoplasmic reticulum as a conduit to human disease. Nature 2016;529:326-335.

-37 Roussel BD, Kruppa AJ, Miranda E, Crowther DC, Lomas DA, Marciniak SJ: Endoplasmic reticulum dysfunction in neurological disease. Lancet Neurol 2013;12:105-118.

-38 Fernández A, Ordóñez R, Reiter RJ, González-Gallego J, Mauriz JL: Melatonin and endoplasmic reticulum stress: relation to autophagy and apoptosis. J Pineal Res 2015;59:292-307.

-39 Lin CJ, Lee CC, Shih YL, Lin CH, Wang SH, Chen TH, Shih CM: Inhibition of mitochondria- and endoplasmic reticulum stress-mediated autophagy augments temozolomide-induced apoptosis in glioma cells. Plos One DOI: $10.1371 /$ journal.pone.0038706.

40 Bauer MR, Joerger AC, Fersht AR: 2-sulfonylpyrimidines: mild alkylating agents with anticancer activity toward p53-compromised cells. P Natl Acad Sci Usa 2016;113:E5271-E5280.

41 Han J, Back SH, Hur J, Lin YH, Gildersleeve R, Shan J, Yuan CL, Krokowski D, Wang S, Hatzoglou M: Erstress-induced transcriptional regulation increases protein synthesis leading to cell death. Nat Cell Biol 2013;15:481-490.

42 Valente L, Gray DD, Michalak E, Pinon-Hofbauer J, Egle A, Scott C, Janic A, Strasser A: P53 efficiently suppresses tumor development in the complete absence of its cell-cycle inhibitory and proapoptotic effectors p21, puma, and noxa. Cell Rep 2013;3:1339-1345.

43 Ghosh AP, Klocke BJ, Ballestas ME, Roth KA: Chop potentially co-operates with Foxo3a in neuronal cells to regulate Puma and Bim expression in response to ER stress. Plos One DOI: 10.1371/journal.pone.0039586.

-44 Hosseinzadeh A, Kamrava SK, Joghataei MT, Darabi R, Shakeri-Zadeh A, Shahriari M, Reiter RJ, Ghaznavi H, Mehrzadi S: Apoptosis signaling pathways in osteoarthritis and possible protective role of melatonin. J Pineal Res 2016;61:411-425.

45 Tan DX, Hardeland R, Manchester LC, Paredes SD, Korkmaz A, Sainz RM, Mayo JC, Fuentes-Broto L, Reiter RJ: The changing biological roles of melatonin during evolution: from an antioxidant to signals of darkness, sexual selection and fitness. Biol Rev 2010;85:607-623.

-46 Reiter RJ, Mayo JC, Tan DX, Sainz RM, Alatorre-Jimenez M, Qin L: Melatonin as an antioxidant: under promises but over delivers. J Pineal Res 2016;61:253-278.

-47 Song J, Kim OY: Melatonin modulates neuronal cell death induced by endoplasmic reticulum stress under insulin resistance condition. Nutrients DOI: 10.3390/nu9060593.

48 Liu S, Liang B, Jia H, Jiao Y, Pang Z, Huang Y: Evaluation of cell death pathways initiated by antitumor drugs melatonin and valproic acid in bladder cancer cells. Febs Open Bio 2017;7:798-810.

-49 Fan L, Sun G, Ma T, Zhong F, Lei Y, Li X, Wei W: Melatonin reverses tunicamycin-induced endoplasmic reticulum stress in human hepatocellular carcinoma cells and improves cytotoxic response to doxorubicin by increasing chop and decreasing survivin. J Pineal Res 2013;55:184-194.

50 Ji YL, Wang H, Meng C, Zhao XF, Zhang C, Zhang Y, Zhao M, Chen YH, Meng XH, Xu DX: Melatonin alleviates cadmium-induced cellular stress and germ cell apoptosis in testes. J Pineal Res 2012;52:71-79.

-51 Othman AI, Edrees GM, El-Missiry MA, Ali DA, Aboel-Nour M, Dabdoub BR: Melatonin controlled apoptosis and protected the testes and sperm quality against bisphenol A-induced oxidative toxicity. Toxicol Ind Health 2016;32:1537-1549.

52 Reda A, Albalushi H, Montalvo SC, Nurmio M, Sahin Z, Mi H, Geijsen N, Toppari J, Söder O, Stukenborg JB: Knock-out serum replacement and melatonin effects on germ cell differentiation in murine testicular explant cultures. Ann Biomed Eng 2017;45:1-12.

53 Niu B, Li B, Wu C, Wu J, Yan Y, Shang R, Bai C, Li G, Hua J: Melatonin promotes goat spermatogonia stem cells (sscs) proliferation by stimulating glial cell line-derived neurotrophic factor (gdnf) production in sertoli cells. Oncotarget 2016;7:77532-77542.

-54 Liu J, Clough SJ, Hutchinson AJ, Adamahbiassi EB, Popovskagorevski M, Dubocovich ML: MT1 and MT2 melatonin receptors: a therapeutic perspective. Annu Rev Pharmacol Toxicol 2016;56:361-383.

55 Quan X, Wang J, Liang C, Zheng H, Zhang L: Melatonin inhibits tunicamycin-induced endoplasmic reticulum stress and insulin resistance in skeletal muscle cells. Biochem Biophys Res Commun 2015;463:1102-1107.

-56 Khalil EK, Amandine V, Olivier D, Alessia B, Clément N, William B, Martine B, Mélanie B, Laurence H, Géraldine M: Endoplasmic reticulum stress drives proteinuria-induced kidney lesions via lipocalin 2. Nat Commun DOI: $10.1038 /$ ncomms10330.

57 Feng D, Wang B, Wang L, Abraham N, Tao K, Huang L, Shi W, Dong Y, Qu Y: Pre-ischemia melatonin treatment alleviated acute neuronal injury after ischemic stroke by inhibiting endoplasmic reticulum stress-dependent autophagy via PERK and IRE1 signalings. J Pineal Res DOI: 10.1111/jpi.12395.

-58 Bu LJ, Yu HQ, Fan LL, Li XQ Wang F, Liu JT, Zhong F, Zhang CJ, Wei W, Wang H: Melatonin, a novel selective ATF-6 inhibitor, induces human hepatoma cell apoptosis through cox-2 downregulation. World J Gastroenterol 2017;23:986-998. 